\title{
Els jueus catalans i les traduccions medievals de la Bíblia Pere Casanellas
}

\section{Les Ilengües parlades pels jueus}

1. Abans del segle $x \mathrm{dC}$ hi ha poques notícies de la presència de jueus als territoris dels actuals Països Catalans. Mentre que hi ha alguna diàspora jueva molt anterior a l'era cristiana, com ara la d'Alexandria (on va tenir lloc la traducció de l'Antic Testament al grec, l'anomenada versió del Setanta), a la Mediterrània occidental, en canvi, els jueus s'hi van establir probablement a partir de la primera revolta jueva i la destrucció de Jerusalem pels romans, l'any $70 \mathrm{dC}$, i sobretot a partir de la segona revolta jueva, dels anys 132-135 dC, capitanejada per Ximon bar Kokhebà. Sufocada la revolta, els jueus van ser expulsats de Palestina i van iniciar el seu exili per les diverses terres de l'imperi Romà (Orient i les costes del Mediterrani). Algunes notícies de la presència dels jueus durant els primers segles de l'era cristiana als actuals territoris de Catalunya i els Països Catalans ens les donen una làpida de Tarragona amb el símbol jueu de la menorà, del segle vi; un epitafi a Tortosa amb text hebreu del mateix segle (l'autenticitat de la qual ha estat posada en qüestió), i a Menorca, la lletra en llatí del bisbe Sever sobre la conversió dels jueus de l'illa l'any 418. També es refereixen als jueus les lleis godes ${ }^{1} i$ les disposicions dels concilis de Toledo. ${ }^{2}$

És, però, a partir de la reconquesta del territori que havien ocupat més o menys llargament els àrabs, que tenim notícies i documentació que ens informen d'una manera més detallada de la pre-

1. La Lex Romana Visigothorum, promulgada l'any 506, proscrivia els jueus dels càrrecs públics, els matrimonis mixtos, la construcció de noves sinagogues, etc. Sisebut l'any 616 va ordenar que, si els jueus no es convertien, fossin expulsats $i$ els seus béns confiscats.

2. El quart Concili de Toledo, de l'any 633, va reaccionar contra les conversions forçades de jueus decretades per Sisebut. sència dels jueus en territori català. Així, sabem que l'any 898 es van establir vint-i-cinc famílies jueves a Girona provinents del comtat de Besalú, i un pergamí que narra l'atac del cabdill musulmà Almansor l'any 985 a Barcelona conté inscripcions en hebreu i esmenta «unes terres i vinyes que em varen pertocar per la successió dels jueus morts que van perir en el saqueig de Barcelona».3 De fet, diversos documents posteriors a l'atac d'Almansor es refereixen a possessions dels jueus a Barcelona. En els segles XI i XII, els documents que esmenten jueus (documents de compra venda, testaments, cartes de repoblament, els mateixos Usatges de Barcelona, etc.) ja són més abundants. És en el segle XIV quan s'arriba a la màxima densitat de població jueva: segons Jaume Riera i Sans (2011-12: 10), potser uns 10.000 o 12.000 entre els anys 1320 i 1348 (a Catalunya, no a la Corona Catalanoaragonesa). Les poblacions on tenim constància de la presència de jueus en aquesta època són abundants, però la població jueva sempre hi va constituir una minoria, potser entre un $4 \%$ i un 7\% de la població total (Riera i Sans 2011-12: 10). A partir dels avalots i la destrucció dels calls de l'any 1391, el nombre de jueus va quedar reduït a una quarta part i va augmentar molt el nombre de conversos. Quan el 1492 els Reis Catòlics van promulgar el decret d'expulsió només van sortir del país unes 200 famílies.

Aquests jueus es van integrar lingüísticament al país d'acollida, i no sols van aprendre català sinó que va esdevenir la seva llengua materna. És lògic, perquè aquestes famílies jueves hi van viure durant diverses generacions; encara que els qui acabaven d'immigrar potser no parlaven un català fluid, segur que els seus fills i néts sí que ho feien. Així es desprèn dels mateixos escrits

3. Citat, en aquesta versió catalana, en Planas i Forcano (2009: 26); l'original és en llatí. 
en hebreu, per exemple els dictàmens o responsa, en què sovint, intercalades al text hebreu, hi apareixen paraules catalanes. Però sobretot és en la transcripció de les declaracions dels testimonis i dels acusats dels processos judicials on queda ben clar que parlen català, i un català idèntic al dels altres catalans amb qui conviuen, tot i mantenir un cert aillament dins els calls. Convé tenir en compte que els documents judicials intenten transcriure amb la màxima fidelitat allò que els testimonis i els acusats declaren, i en aquest sentit són un testimoni molt fidel de la seva parla. Afegim encara que alguns jueus van escriure obra literària en català, com és el cas dels proverbis de Mossè Natan, de Tàrrega ( $†$ 1359/60). Ell mateix va escriure també un recull de proverbis en hebreu, que ha estat objecte d'una tesi doctoral (Muntané i Santiveri 2010). La seva obra catalana, majoritàriament perduda, constava d'un tractat o romanç religiós i moral (del qual només es conserven els dos primers versos i trenta més conservats en una traducció castellana) i d'uns proverbis en apariats octosillàbics de rima consonant o noves rimades (dels quals només se'n conserven un parell en un florilegi d'un autor mallorquí del segle Xv). Hem de

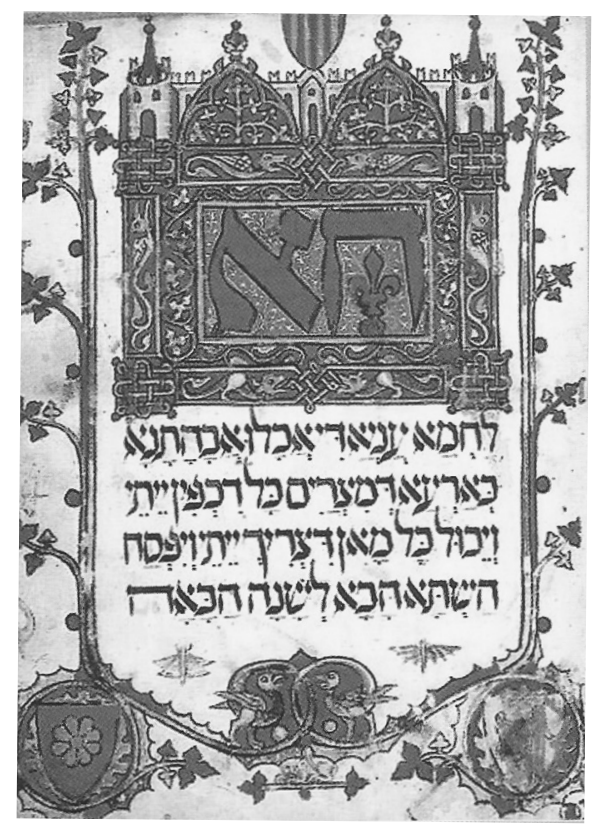

Hagadà de Sarajevo del segle XIv. És probable que el manuscrit fos illuminat a la Corona d'Aragó després de 1350, d'on va partir cap a Itàlia i els Balcans amb l'expulsió de 1492 (Museu Nacional de Sarajevo, f. 3). destacar sobretot l'obra catalana del seu coetani Jafudà ben Astruc Bonsenyor († 1331), compilador i traductor del Llibre de paraules e dits de savis e filòsofs, escrit el 1289 per manament reial de Jaume II, que volia en romanç un compendi de màximes morals extretes de llibres aràbics.

S'ha de tenir en compte, però, que al País Valencià i a les Balears els jueus havien viscut durant molt de temps sota la dominació àrab i havien adoptat l'àrab com a llengua pròpia. D'altres jueus sabien àrab perquè havien immigrat de països de parla aràbiga.

A banda de la seva llengua materna o familiar, en general el català o l'àrab, els jueus medievals sabien hebreu, que era la seva llengua de lectura de la Bíblia (l'Antic Testament) i del nucli del Talmud (la Mixnà), la llengua de la pregària i la llengua amb què van escriure obres exegètiques, teològiques i filosòfiques que encara avui són reeditades i estudiades pels jueus d'Israel i d'arreu del món. Esmentem, per exemple, quatre noms de primera categoria dins el judaisme: Mossè ben Nahman, anomenat també Nahmànides, de Girona (1194-1270), especialment conegut pel seu Comentari al Pentateuc i també per la disputa pública que mantingué amb fra Pau Cristià davant el rei Jaume I l'any 1263; Salomó ben Adret, de Barcelona (1235-1310), ben conegut pels seus dictàmens; el filòsof Hasday Cresques, de Barcelona (ca. 1340-1410/11); i el gramàtic i polemista contra el cristianisme Profiat Duran, potser de Perpinyà (ca. 1350-ca. 1414), autor d'Al tehí ka-avoteka i Ma‘aśe Efod.

Alhora que l'hebreu, havien de conèixer l'arameu, pel fet de ser la llengua de la major part del Talmud (la Guemarà) i d'algunes pregàries, una llengua germana de l'hebreu, que li és particularment pròxima.

Altres jueus havien immigrat d'altres països i tenien coneixement d'altres llengües, especialment de l'aragonès, el castellà, el provençal i l'àrab.

\section{Els jueus com a traductors}

2. Molts jueus, per aquest coneixement que tenien de les llengües, es van poder dedicar a fer de torsimanys i traductors de textos. Al- 


\section{Els Tibònides}

- Judà ben Saül ibn Tibon (1120-ca. 1190) es va installlar a Lunel (prop de Montpeller), una població que havia d'esdevenir un centre important dedicat a les traduccions de l'àrab a l'hebreu. Va traduir el Llibre de les creences de les conviccions de Seadyià Gaon i el Llibre del Kuzari de Yehudà ha-Leví.

- Samuel ibn Tibon (1150-1230), el seu fill, va ser el més cèlebre dels Tibònides. Gràcies a la traducció que va fer el 1204 de la Guia dels perplexos (1196) de Maimònides, va ser nomenat «pare dels traductors». Va traduir també la Meteorologia d'Aristòtil, obres d'Averrois, el Tractat sobre el moviment dels estels fixos d'Al-Zarqali conegut com a Azarquiel, el comentari de Maimònides sobre el tractat Avot, etc.

— Mossè ben Tibon (actiu de 1240 a 1285) i altres membres de la família Tibònides també van contribuir a les traduccions de l'àrab a l'hebreu.

— Profeit Tibon (Jacob ben Mahir, Marsella? 1230-Montpeller 1312) parent d'aquests Tibònides, va traduir el tractat astronòmic d'al-Zarqali o Azarquiel, publicat amb el títol de Tractat de l'assafea d'Azarquiel per J. M. Millàs i Vallicrosa.

guns van fer de diplomàtics i torsimanys, a sou del rei, pels regnes musulmans de la península i també als països musulmans de la Mediterrània: Salomó Alconstantiní, en temps de Jaume I; Astruc Bonsenyor, pare de l'abans esmentat Jafudà Bonsenyor, en temps de Jaume I; i els germans Samuel i Jafudà Abenmenassè, en temps de Pere III, entre altres.

Com a traductors, els jueus van traslladar a I'hebreu obres filosòfiques i científiques àrabs, moltes de les quals al seu torn ja hi havien estat traduïdes del grec o del siríac. També van traduir a l'hebreu obres escrites en àrab per jueus arabitzats, destinades als seus correligionaris desconeixedors de l'àrab, i obres escrites en llatí. Van actuar així com a transmissors i introductors de la filosofia i la ciència gregues i àrabs a Europa.

Entre les obres científiques, mereixen una consideració a part les obres mèdiques, traduïdes també de l'àrab o del llatí a l'hebreu, i de l'àrab al català. Així, Semtob ben Issac, el Tortosí (ca. 1196-d. de 1267) va traduir de l'àrab a l'hebreu el Kitab al-Tașrif («El llibre de la pràctica mèdica») del metge andalusí Abu-l-Qāsim al-Zahrawī, conegut com a Abulcasis (ca. 936-ca. 1013) i considerat per alguns com el pare de la cirurgia (Feliu \& Arrizabalaga 2000-01). Abraham Judaeus de Tortosa (de final del segle XIII), amb Simon de Gènova, el va traduir al llatí: Liber servitoris. Jaume II, segons un document de l'any 1313, encarregà la traducció d'aquesta obra al català a un altre jueu, Jafudà, fill d'Astruc Bonsenyor (ca. 1250-ca. 1330).

El Regiment de sanitat d'Arnau de Vilanova, escrit en llatí entre 1305 i 1308, va ser traduït de la seva versió catalana a l'hebreu (en versió completa) el 1466 per Samuel ben David Eben-Soham i més tard per Jucef ben Jafudà ha-Sefaradí. El Medicationis Parabole, també d'Arnau de Vilanova, va ser traduït per Abraham Abigdor (Arles 1350-?).

\section{JUEUS I CONVERSOS, TRADUCTORS DE LA BíBLIA?}

3. Els jueus, doncs, estaven ben preparats per a l'ofici de la traducció, i l'exercien, principalment amb textos filosòfics, religiosos i científics. Van traduir també textos bíblics?

En realitat, ja hem vist que els jueus de la Catalunya medieval, com en general els de totes les èpoques, llegien la Bíblia (és a dir, el nostre Antic Testament) en hebreu i no els calia cap traducció al català. De tota manera, des de temps antics hi ha hagut excepcions. Així, a Alexandria, durant els segles $\|-\|$ aC la Bíblia hebrea es va traduir al grec per a ús dels jueus de la diàspora hellenitzats; és la versió anomenada dels Setanta. I durant els primers segles de l'era cristiana, la Bíblia hebrea va ser traduïda a l'arameu, sovint en traducció parafràstica, perquè hi

4. Vegeu Feliu (2006-07). 
tinguessin accés els jueus que ja no tenien l'hebreu sinó l'arameu per llengua materna. De fet, en època medieval no tots els jueus dominaven l'hebreu, especialment les dones.

D'altra banda, si ens fixem ara, no en les traduccions de l'hebreu a altres llengües, sinó en les d'altres llengües a l'hebreu: ¿els jueus medievals podien tenir interès a traduir el Nou Testament a l'hebreu? Amb quina finalitat?

Avui tenim la sort que el projecte Corpus Biblicum Catalanicum (CBCat) ha començat a editar el corpus de les traduccions bíbliques catalanes medievals (tot i que gran part d'aquestes edicions no han estat encara publicades) i això ens permet estudiar la intervenció de jueus i de conversos en la tasca de traducció amb molta més facilitat i fiabilitat que fa uns quants anys. ${ }^{5}$ S'ha de tenir en compte que la versió llatina de sant Jeroni no és sempre totalment ajustada a l'original hebreu que tradueix, o almenys al text hebreu que ha arribat fins a nosaltres, i això permet que, allà on l'original hebreu i la traducció llatina divergeixen, es pugui comprovar si la versió catalana tradueix el llatí o l'hebreu. També es donen casos en què el text hebreu pot tenir més d'un sentit, i es pot comprovar si la versió catalana manté el mateix sentit que la Vulgata o no.

\section{Influències hebrees en la part traduïda de la Vulgata a la Bíblia del segle XIV}

4. Al llarg del segle XIV es va elaborar la primera traducció completa de la Bíblia al català, l'única que ens ha arribat sencera. L'anomenem Bíblia del segle XIV, tot i que l'Antic Testament s'ha conservat en manuscrits del segle Xv. Gran part de la traducció es devia fer a l'època del rei Pere III el Cerimoniós (1336-87), quan la casa reial catalana va fomentar molt les traduccions, especialment dels clàssics llatins. L'Antic Testament es conserva principalment en tres manuscrits, de la segona meitat del segle $x V$, que anomenem Peiresc $(P)$,

5. De la Bíblia del segle xIv (vegeu l'apartat següent) n'han estat publicats durant els últims anys els llibres de l'Èxode i el Levític (volum 3 del CBCat) i els Primer i Segon llibre dels Reis (volum 6 del CBCat). Molts altres volums s'estan preparant per a la publicació. Vegeu el web http://cbcat.abcat.cat/ i Casanellas (2005).
Egerton (E) i Colbert (C). Peiresc inclou la Bíblia sencera, mentre que Egerton i Colbert només en contenen la meitat, des del llibre del Gènesi fins al llibre dels Salms. En el CBCat s'editen els manuscrits catalans en columnes paralleles (en la primera part de la Bíblia, present en tots tres) perquè tenen massa diferències per a poder-los reduir a un sol text i, a més, de vegades aporten versions totalment independents. En una altra columna, a l'esquerra, s'edita el text de la Vulgata, tenint en compte que és l'original principal de la traducció. I s'acompanya amb dos aparats crítics: el de la versió crítica de Stuttgart i un aparat propi del CBCat, elaborat a partir de quatre vulgates del territori on es va elaborar la versió catalana (vulgates de Montpeller, segles XII-XIII; de Girona, primera meitat del segle XIII; de Vic, any 1268, i de Tarragona, inici del segle XIV).

Aquesta Bíblia ens interessa molt perquè, tot i que aparentment la traducció és feta de la Vulgata llatina i per a ús de cristians, conté diversos elements presos de l'original hebreu de l'Antic Testament, i presenta algunes influències de la tradició jueva postbíblica. Ens fixarem en els llibres de l'Ėxode i el Levític (volum 3 del CBCat), que són els que presenten més influència hebrea de tots els publicats i dels que hem estudiat fins ara. ${ }^{6}$

\section{LA VULGATA COM A ORIGINAL PRINCIPAL}

4.1. El primer que es dedueix de la confrontació del text de la traducció catalana amb el text de la Vulgata i el text hebreu és que la traducció catalana segueix generalment el text llatí de la Vulgata. Les abundants notes collocades al peu de les columnes de l'edició dels tres manuscrits catalans mostren com el text s'explica en general per la Vulgata o per les seves diferents lliçons variants. El text d'Ex 1,13 pot ser una bona mostra per a veure com el text és traduït de la Vulgata i no de l'hebreu (el copiem del ms. Peiresc, vegeu el quadre 1).

De la comparació del text català amb l'hebreu i el llatí, és clar que aquest és l'original de la traducció. A més, només la variant llatina et

\footnotetext{
6. En aquest apartat ens limitem a resumir el que vam exposar en Casanellas (2006).
} 
invidentes (exclusiva d'algunes vulgates catalanes) explica els mots catalans e anvejàvan-los.

Molts afegits de la versió catalana s'expliquen únicament pel text de la Vulgata, de vegades per variants llatines testimoniades únicament o especialment per les vulgates autòctones. Un exemple interessant és l'afegit dels mots la bocha no li trenchareu en Ex 12,9 E. Es tracta d'una mala traducció del text llatí nec os illius confringetis ('no li trencareu cap os'; text referit a la víctima pasqual), originada pel doble sentit que pot tenir en llatí el mot os ('os' i 'boca'). L'afegitó ha estat pres del v. 46, on el text llatí ha estat correctament traduit (no trenquareu os d'aquell); per tant, el fet que en el v. 9 el mot llatí os estigui incorrectament traduït significa que l'afegitó no prové del text català del v. 46, ni tampoc de l'original hebreu del v. 46, sinó molt probablement de l'original llatí que el traductor tenia a mà. I, en efecte, en la Vulgata de Vic, en el v. 9 trobem el text et os eius non confringetis en una nota marginal.

La traducció de terminologia també deixa veure sovint que el text original és la Vulgata. Així, el terme hebreu אִיפָה (efà), que designa una mesura de capacitat emprada per a sòlids, equivalent a uns 21 litres, és traduït en la Vulgata per la forma ephi. En els tres manuscrits catalans de la Bíblia del segle XIV aquest terme és traduit per efí, transcripció de la forma llatina i no pas de l'hebrea.

A Ex 28,4, Egerton, que aquí ofereix la seva pròpia traducció, sembla que no ha sabut com traduir el mot llatí cidarim 'tiara' i l'ha transcrit amb la mateixa forma en acusatiu (nominatiu: cidaris) amb què apareix en el text llatí: sidarim.

El mot hebreu שִׁים (xittim) designa la fusta de què es féu l'arca de l'aliança i el tabernacle, que els autors actuals coincideixen a dir que es tracta de l'acàcia. Però la Vulgata es limita a transcriure el terme amb la forma setthim. Els manuscrits de la Bíblia del segle XIV fan servir les formes setim, ${ }^{8}$ sethim, ${ }^{9}$ i satim, ${ }^{10}$ que semblen transcripció de la forma llatina més que

7. Vegeu Ex 16,36 P i C; Lv 5,11 P, E i C.

8. Ex 25,5 C; $25,10.13 \mathrm{P}$ i C; etc.

9. Ex 36,31C; $37,10 \mathrm{C}$; etc.

10. Ex 25,23 P; 26,15.32 P; etc.

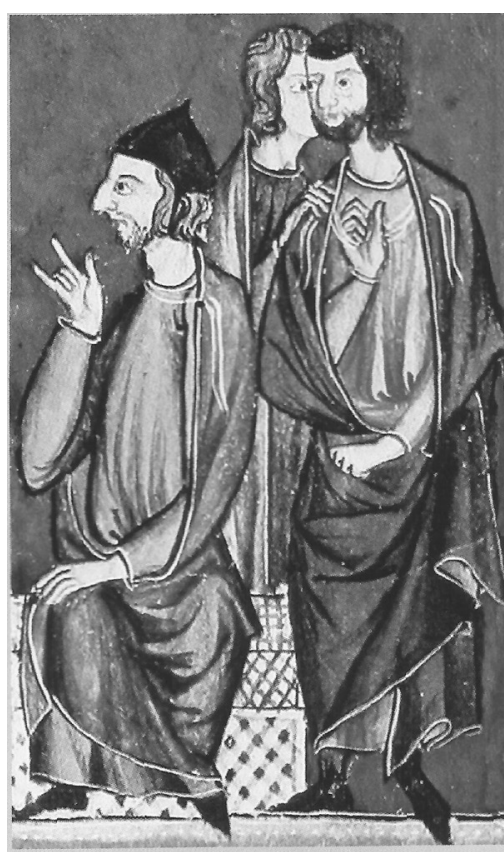

Jueus debatent al Libro de ajedrez d'Alfons X (Escorial, Biblioteca del monestir, ms T-I-6, f. 2 or (1283).

no pas de l'hebrea, per la e després de la primera consonant. ${ }^{11}$

Diversos errors de traducció només s'expliquen per un original llatí.

LES INFLUÈNCIES DEL TEXT HEBREU

4.2. Encara que la traducció es fes bàsicament a partir del text de la Vulgata, s'hi detecta una gran influència de la Bíblia hebrea. Les notes del volum Bíblia del segle XIV: Ėxode. Levític criden l'atenció del lector sobre més de cent llocs, la majoria al llibre del Levític, on la versió catalana sembla basar-se en el text hebreu.

Alguns noms propis es prenen de l'hebreu i no pas de la Vulgata. Així Siporà (Ex 2,21 P i C; vegeu també 18,2) correspon a l'hebreu צִָּּרָ (Sipporà), mentre que totes les vulgates porten la forma Sephoram (o bé Sefforam). Garson/Guarson (Ex 2,22 P i C; vegeu també 18,3) amb o en lloc

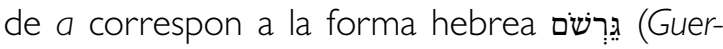
xom) — que també es troba en la vulgata catalana de Tarragona - i no a la forma general de les vulgates Gersam/Gersan; cal tenir en compte que

11. Respecte a la presència de la $s$ en lloc de la $x$ que algú podria esperar, vegeu l'apartat següent. 


\begin{tabular}{|c|c|c|}
\hline Text hebreu i trad. literal & Bíblia del segle XIV & Vulgata i trad. literal \\
\hline 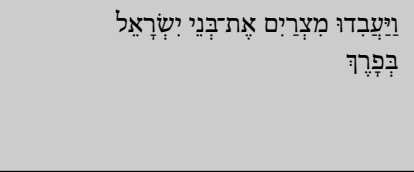 & $\begin{array}{l}\text { E los agepcians haguéran en } \\
\text { oy los fills de Israel, e opre- } \\
\text { mien-los e·scarnían-los e an- } \\
\text { vejàvan-los }\end{array}$ & $\begin{array}{l}\text { oderant-que filios Israhel } \\
\text { Aegyptii et affligebant illu- } \\
\text { dentes eis [+ et invidentes] }\end{array}$ \\
\hline $\begin{array}{l}\text { 'I els egipcis van esclavitzar } \\
\text { els fills d'Israel amb duresa' }\end{array}$ & & $\begin{array}{l}\text { 'I els egipcis odiaven els fills } \\
\text { d'Israel i els afligien escar- } \\
\text { nint-los [+ i envejant-los]' }\end{array}$ \\
\hline
\end{tabular}

En aquest quadre i en el següent escrivim, en la primera fila, el text hebreu a l'esquerra, la versió de la Bíblia del segle XIV al centre i el text de la Vulgata, a la dreta; en la segona fila donem una traducció molt literal del text hebreu i del text de la Vulgata. Subratllem els elements en què la versió catalana coincideixnomés amb una de les dues possibles fonts: la Vulgata o el text hebreu. En tots els exemples de l'article el text llatíés pres de la Vulgata sixtoclementina, un text proper al de les vulgates que hi havia en territori català quan es van elaborar les versions catalanes de la Bíblia.

els jueus medievals pronunciaven la consonant xin, que trobem en aquest nom hebreu ( $x$ en la transcripció), com a alveolar fricativa sorda (com la essa sorda del català) i no amb el so palatal fricatiu sord (com el de la xeix del mot català caixa) que té en hebreu clàssic i modern.

$\mathrm{Hi}$ ha terminologia presa directament de l'hebreu. Així la designació mes de l'espiga (Ex 13,4 P i C; 34,18 P i C), per al mes hebreu que actualment anomenem mes d'aviv, procedeix de la forma he-

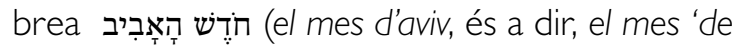
l'espiga') i no pas de la forma llatina mense novarum frugum 'mes de les noves collites'. El terme hossen (Ex 28,26 C; 28,29,30 P i C; etc.), emprat per a designar la peça de la vestidura del gran sacerdot que les versions catalanes modernes anomenen pectoral o bossa pectoral, és mera transcripció del mot hebreu חשֶׁן (hoixen; recordem que la xin hebrea en català medieval es pronunciava amb el so d'essa sorda), mentre que la Vulgata tradueix aquest mot per rationale (d'on procedeixen les formes variants catalanes racional i raonal, que trobem especialment en el manuscrit Egerton, que tendeix a evitar els hebraismes i a cenyir el text a l'original llatí), etc.

Alguns afegits que tenen els manuscrits catalans respecte al text de la Vulgata procedeixen de l'original hebreu.
Algunes males traduccions de la versió catalana s'expliquen per males interpretacions del text hebreu. En Ex 35,19 P i C, el mot santedat correspon, en la Vulgata, a la forma sanctuarii; el mot català és en realitat traducció del mot hebreu קדְָׁש (qódeix) que tant pot significar 'santedat' (així l'interpreta el traductor català) com 'santuari' (interpretació de la Vulgata). En LV 10,19, en els tres manuscrits catalans, la segona part del verset ha estat traduïda primer a partir de la Vulgata i després ha estat tornada a traduir a partir de l'hebreu; en efecte, en aquest duplicat, a la forma llatina accidit ('ha esdevingut'), correspon el verb català cridaren: no és difícil veure que la mala traducció té per origen l'existència de dos verbs homònims en hebreu: קרא (que trobem en l'original hebreu) pot significar 'esdevenir' i pot significar 'cridar'.

Unes quantes dotzenes de notes del volum Bíblia del segle XIv: Ėxode. Levític avisen el lector de diversos llocs on la versió catalana s'aparta de la Vulgata i segueix el text hebreu. En el quadre 2 en mostrem un sol exemple, pres d'Ex 32,18 P i C (el darrer vers del breu poema que constitueix el verset sembla que retorna a l'original llatí):

També en el Primer i Segon llibre dels Reis apareixen algunes influències de l'hebreu, si bé són menys nombroses (CBCat, vol. 6: 31). Esmentem, 


\begin{tabular}{|c|c|c|}
\hline Text hebreu i trad. literal & Bíblia del segle XIV & Vulgata i trad. literal \\
\hline 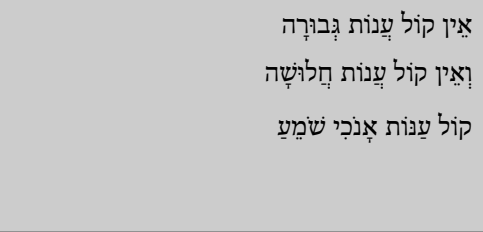 & $\begin{array}{l}\text { No és veu } \\
\text { de resposta de fortesa } \\
\text { e tanpoch no és veu } \\
\text { de resposta de flaquesa, } \\
\text { mas yo veg que veu és } \\
\text { d'hòmens cantans. }\end{array}$ & $\begin{array}{l}\text { Non est clamor } \\
\text { adhortantium ad pugnam, } \\
\text { neque vociferatio } \\
\text { compellentium ad fugam: } \\
\text { sed vocem cantantium } \\
\text { ego audio. }\end{array}$ \\
\hline $\begin{array}{l}\text { 'No és el so de cants/ } \\
\text { resposta de força, } \\
\text { ni el so } \\
\text { de cants/resposta } \\
\text { de debilitat/prostració; } \\
\text { so de càntics } \\
\text { és el que sento.' }\end{array}$ & & $\begin{array}{l}\text { 'No és el clamor de gent } \\
\text { que exhorta al combat, } \\
\text { ni vociferació } \\
\text { dels qui inciten a la fuga, } \\
\text { sinó que sento } \\
\text { veu de gent que canta.' }\end{array}$ \\
\hline
\end{tabular}

com a exemple, la forma Mossè (1Re 12,6 P) en lloc de l'habitual Moysès, coincidint amb la forma amb què els jueus pronunciaven el nom hebreu de Moisès en els territoris catalans en època medieval. La mateixa forma apareix també en Ex 4,10 C.

\section{ALTRES INFLUÈNCIES JUDAIQUES}

4.3. Tant o més interessants que les influències del text bíblic hebreu en la Bíblia del segle XIV són algunes altres influències de la tradició judaica que s'hi poden detectar.

a) La duració de la festa de Pasqua.- En Ex 12,16, el text bíblic hebreu prescriu que el primer dia i el setè de la festa dels Àzims (una festa que es va unificar amb la de Pasqua) són dies d'aplec sagrat en què no es pot treballar. La Vulgata ho tradueix així: «Dies prima erit sancta atque solemnis, et dies septima eadem festivitate venerabilis: nihil operis facietis in eis, exceptis his quae ad vescendum pertinent». La versió de Peiresc i Egerton afegeix al primer dia festiu un segon dia, d'acord amb la tradició jueva postbíblica segons la qual a la diàspora són festius no solament el primer dia i el setè de la celebració pasqual, sinó també el segon i el vuitè: «Lo primer dia e al sagon serà encara de gran festa e solempnitat [.. . ]». Per tant, sembla clar que el traductor era un jueu o un convers que tenia consciència que el segon dia també era festa (perquè a la diàspora, on ell vivia, ho era).

b) Traduccions coincidents amb el Targum. - En dos llocs la versió catalana no s'explica ni per la
Vulgata en cap de les variants registrades, ni pel text hebreu, ni tampoc pel text grec dels Setanta i, en canvi, coincideix amb el Targum, l'antiga versió aramea de l'Antic Testament.

En Ex 21,6, el text hebreu explica el procediment que cal seguir quan, arribat el setè any (és a dir, l'any sabàtic) de servei d'un esclau, aquest renuncia a quedar lliure: el seu amo l'ha de portar אֶל־הֶֶֶלהָים 'a Déu' o 'als déus', li ha de foradar l'orella amb un punxó i serà esclau seu per sempre. Els mots hebreus citats són interpretats com a plural per la Vulgata: diis 'als déus'. La versió grega dels Setanta té una interpretació diferent, que explica el sentit del text: זрòs tò kpıtńpıov тoũ Өcoũ 'al tribunal de Déu'. La traducció de la Bíblia del segle XIV s'aparta de totes aquestes versions i coincideix amb l'antiga versió aramea o Targum:

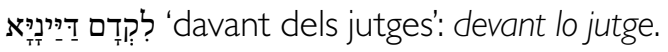

Semblantment s'esdevé en Ex 22,8, on el text bíblic es refereix al lloc on ha d'acudir l'amo d'una casa a qui han estat robats objectes deixats en dipòsit sense que se n'hagi descobert el lladre: segons la Vulgata s'ha de presentar ad deos; segons la versió catalana de Peiresc i Egerton, al jutge, coincidint de nou amb el Targum.

c) Altres mostres de l'exegesi rabínica. - En Ex 22,20, tant el text hebreu, com la Vulgata i la versió dels Setanta es poden traduir de la mateixa manera: «Qui ofereixi sacrificis a altres déus fora del Senyor, serà consagrat a l'extermini». La versió catalana de Peiresc i Egerton, en canvi, substitueix els altres déus per el diable 
(«Qui ferà sacrifici al diabla, sia destrovit. No deu haver sacrifici sinó Déu»), d'acord amb una exegesi jueva testimoniada en altres textos (Gutwirth 1988: 130).

\section{La intervenció dels conversos en la Bíblia del segle XIv i en la Bíblia del segle XV o Bíblia Valenciana}

5. Hi ha, doncs, en certes parts de la Bíblia del segle XIV, una influència del text original hebreu que sembla que es mantingui latent al llarg de la traducció i que només es manifesta de tant entant, sovint de maneres subtils: en l'onomàstica, en la terminologia, en la traducció de part d'un verset, etc. Aquestes influències subtils del text bíblic hebreu, afegides a algunes influències de la tradició judaica postbíblica no creiem que es puguin explicar perquè un copista tingués al davant un exemplar de la Bíblia traduit de la Vulgata i un altre traduït de l'hebreu, i en seguís ara l'un, ara l'altre, dels dos exemplars. Més aviat creiem que s'expliquen perquè el traductor estava ben familiaritzat amb el text original hebreu i amb la tradició rabínica, i introduiia més o menys conscientment elements d'aquesta cultura seva en traduir el text de la Vulgata. La hipòtesi que sembla més

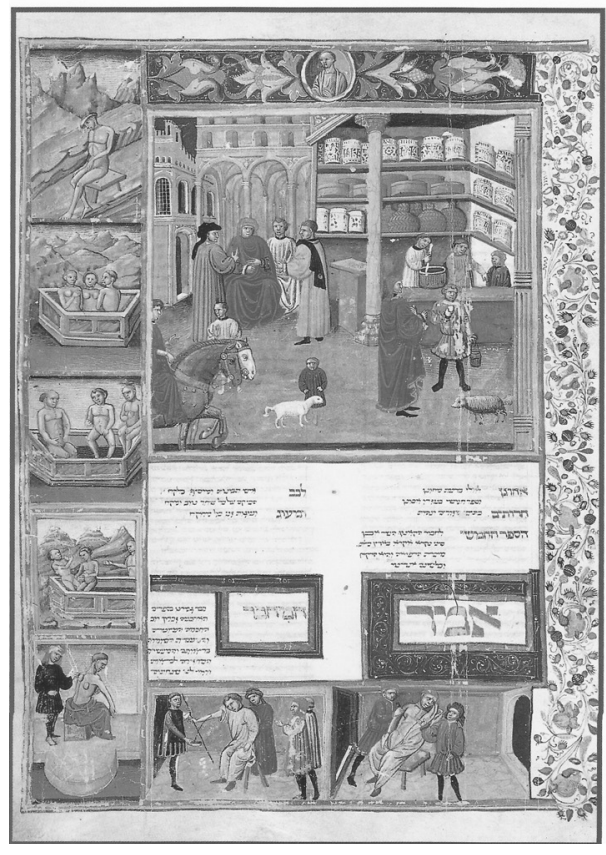

Cànon d'Avicenna (segle xv, Bolonya, Biblioteca Universitaria, ms. 2197, f. 492r). plausible és que la versió de la Bíblia del segle XIV va ser una obra encarregada per cristians i realitzada per conversos jueus que, tot i que pretenien traduir el text a partir d'algun exemplar o alguns exemplars de la Vulgata, constantment hi introduien elements de l'original hebreu de la Bíblia (noms propis, terminologia, traduccions del text que potser tenien memoritzades) $i$ altres elements de la tradició rabínica. Altres detalls escadussers, com per exemple la presència aïllada de la forma Mossè en textos en què la forma general és Moysès, es poden explicar per la intervenció de copistes (no de traductors) conversos.

La intervenció de conversos, en general, en la confecció de les traduccions bíbliques no és sols una hipòtesi. La tenim documentada en l'elaboració d'una traducció bíblica, la Bíblia del segle XV - Bíblia Valenciana (impresa a València el 1478), atribuïda (segons el colofó) a Bonifaci Ferrer, si bé en aquest cas la missió del convers que treballà en la preparació del text per a la impremta va anar en sentit contrari al que acabem de veure: va ser precisament corregir d'errors el text verificant-lo amb l'original de la Vulgata.

D'aquesta Bíblia, a causa de les cremes de bíblies de la Inquisició, només en queda l'últim foli a la biblioteca de la Hispanic Society de Nova York i el contingut del Saltiri, reimprès a Barcelona dos anys més tard. Segons la documentació de la Inquisició estudiada per Jordi Ventura, va ser impulsada, a partir del 1477?, pels conversos Andreu Forcadell, cirurgià, i Daniel Vives, i hi van intervenir algunes personalitats de l'Església valenciana, com el dominicà Jaume Borrell, inquisidor, i Jaume Peres, bisbe auxiliar de València. En el procés inquisitorial s'explica que van buscar una bíblia manuscrita per poder preparar la Bíblia impresa. De primer, van provar amb un exemplar que tenia una llengua massa antiga i el van canviar per l'exemplar, escrit en el català de València, que va aportar el noble Berenguer Vives de Boïl (esmentat també al colofó), i que contenia suposadament la traducció de Bonifaci Ferrer.12 Al pricipi, el convers Daniel Vives

\footnotetext{
12. Curiosament, en el procés de la Inquisició mai no s'allega que aquesta bíblia manuscrita hagués estat traduïda per Bonifaci Ferrer, com seria lògic per defensar-ne la qualitat, la qual cosa reforça les sospites sobre l'atribució que es fa en el colofó.
} 
llegia en veu alta el text bíblic i fra Jaume Borrell, que tenia davant els ulls una bíblia llatina impresa, li deia què havia de corregir. Un cop corregits quatre o cinc quinterns, com que la impressió dels fulls ja havia començat i calia accelerar la feina, Vives es va traslladar a la impremta per fer-hi la correcció de les proves i fra Jaume Borrell, ajudat de fra Bernat Comes, un dominicà més jove, revisava el manuscrit de Berenguer Vives de Boïl al convent. Després van tornar a treballar junts Borrell i Vives, però només el diumenge i en festa, i entre setmana Vives corregia proves a la impremta. Finalment, en una última etapa de la feina, acabà de revisar la traducció Daniel Vives sol, amb les degudes consultes a fra Jaume Borrell i al bisbe Jaume Peres (Ventura 1993: 15-56).

\section{Traduccions de la Bíblia hebrea al català}

6. Disposem de diverses traduccions parcials de la Bíblia hebrea al català, que s'han d'atribuir a autoria de jueus o conversos.

Un SidDUR O MANUAL DE PREGÀrIES PER A ÚS DE CONVERSOS JUEUS

6.1. Del darrer terç del segle $x v$ es conserva un siddur o manual de pregàries, que conté quaranta-un salms, a més d'altres fragments bíblics, traduits de l'hebreu. Conté les oracions quotidianes, del matí i del vespre, i les oracions per al dissabte, el cap de mes i les altres festes de l'any litúrgic jueu, és a dir que conté el que ha de tenir un siddur, però en català, la qual cosa no és normal. El motiu de ser en català és segurament que no era per a ús de jueus, sinó de conversos que devien haver perdut el coneixement suficient de I'hebreu. De fet, era propietat del convers valencià Bartomeu Rodrigues, al qual pertanyia també un altre manuscrit que conté diverses pregàries jueves, d'entre les quals set salms; és remarcable que d'aquests, dos són traduïts de l'hebreu, però els altres cinc contenen la traducció «cristiana», feta pel dominicà Romeu Sabruguera entre 1282 i 1325. Tots dos manuscrits han estat editats per Jaume Riera. Observem que l'escrivà del manuscrit desconeixia l'hebreu, segons demostren els errors que comet en transcriure alguns noms he- breus. Això i altres detalls fan pensar que no es tractava de la traducció d'un siddur autèntic hebreu sinó d'un text escrit, almenys en part, més o menys de memòria. ${ }^{13}$

Amb aquest siddur i aquest llibre de pregàries sabem per primera vegada alguna cosa sobre els destinataris de les traduccions fetes per jueus: el propietari era un convers i sembla que la traducció va ser feta o reelaborada per algun convers.

\section{UN SALTIRI TRADUIIT DE L'HEBREU}

6.2. Entre els diversos saltiris medievals traduits al català que es conserven, en tenim un traduit de l'hebreu a mitjan segle $\mathrm{xV}$, al Regne de Nàpols, sota la protecció d'Alfons el Magnànim, que es conserva en un manuscrit de la primera meitat del segle $\times$ vi. Tot i ser una traducció clara de l'hebreu (amb calcs freqüents), una segona mà el va adaptar a l'ús litúrgic cristià, i fins hi va fer correccions i afegits adaptant-lo a la Vulgata. Per exemple, al marge, al començament de cada salm s'hi va escriure el títol del salm en llatí (en el Salm 1: «Beatus vir quil»; en el Salm 2: «Quare fremuerunt gentes»; etc.); al final d'alguns salms hi ha escrit el Gloria Patri —observem que els edictes i instruccions de la Inquisició denunciaven com a pràctica herètica judaïtzant la recitació dels «salms de David sense Gloria Patri» (Riera i Sans 1993: 11); alguns salms tenen la indicació marginal del dia de la setmana en què es resen, per exemple: diumenge i tots els dies. En aquest moment s'està transcrivint i esperem que es pugui publicar aviat dins el volum 26 del CBCat. ${ }^{14}$ Desconeixem, de moment, la història d'aquesta traducció, però sembla clar que va ser feta per jueus o conversos i per al seu ús.

En les notes de l'edició que s'està preparant, sempre que el text de la Vulgata i l'original hebreu divergeixen o bé que el text hebreu es pu-

13. Siddur: Barcelona, Biblioteca de la Reial Acadèmia de Belles Arts de Sant Jordi, ms. s/ signatura; BITECA, manid 2788; edició i estudi a Riera (1993).— Pregàries jueves: Barcelona, Biblioteca de la Reial Acadèmia de Belles Arts de Sant Jordi, ms. s/ signatura; BITECA, manid 2275; edició i estudi en Riera (1971-75).

14. París, Bibliothèque Nationale de France, ms. esp. 244; BITECA, manid 1954. Veg. Berger (1889-99: 119-20), Bohigas (1985: 79), Puig i Tàrrech (2001: 136-37). 
gui traduir de diverses maneres, es mostra com la traducció segueix l'original hebreu.

\section{Parts d'un Antic Testament del segle XiV} TRADUIIT DE L'HEBREU

6.3. Més amunt ( 4.2 i 4.3 ) hem vist que en la Bíblia del segle XIV, tot i estar traduïda majoritàriament de la Vulgata, s'hi poden detectar influències de la Bíblia hebrea i fins d'altres elements de la tradició judaica. Tanmateix, a mesura que dins el projecte del CBCat es va preparant l'edició dels corresponents manuscrits i s'estudien, s'ha anat veient que en alguns llibres bíblics o grups de capítols, en alguns dels manuscrits editats la traducció no sols té influències hebrees sinó que és feta directament de l'original hebreu. Fins al moment present els textos que hem identificat com a traduïs de l'hebreu són:

a) Llibre de Josuè, manuscrit Colbert, capítols 18 a 24 (enfront dels manuscrits Peiresc i Egerton, que tradueixen la Vulgata). Les notes de l'edició expliquen constantment com la versió catalana de Colbert segueix el text hebreu. Un dels detalls que ho mostren és que, de vegades, els mots genèrics que precedeixen els topònims no es tradueixen sinó que només es transcriuen de l'hebreu, així, la forma «émech Rafaÿm» del ms. Colł bert $(18,16)$ no s'explica per «vallis Raphaim» de la Vulgata sinó per la forma hebrea עֶמֶק רִפָּאִ (émek Refaïm) 'vall de Refaïm'. En moltíssims altres detalls es pot veure com la traducció segueix el text hebreu; per exemple, en 23,2, Josuè diu segons la Vulgata: «Ego senui, et progressoris aetatis sum», frase que és traduïda pels manuscrits Peiresc i Egerton «Yo són vell e de adat avençada» i «Jo sóm vell e de edat avensade», respectivament; en canvi, és clar que la frase de Colbert «Yo sóm vell e de molts dies》 tradueix el text hebreu

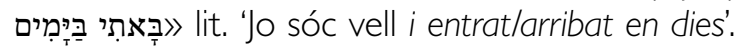
En 24,6, «la Mar Roja» del manuscrit Egerton (Peiresc té aquí una llacuna) correspon a «mare Rubrum» de la Vulgata, mentre que «la mar de Suf» d'Egerton correspon a l'hebreu ים-סוּר (yam Suf), 'la mar de Suf'. Etc.

b) Primer llibre dels Paralipòmens, manuscrits Egerton i Colbert (Peiresc i Sevilla tradueixen la
Vulgata). En els primers nou capítols, dedicats a genealogies, els noms propis ja hi apareixen seguint clarament les formes hebrees: 1,7: Vulgata: «Tharsis»; hebreu: תַרְשׁׁישָה (Tarxixa); Egerton/ Colbert: «Traciza/Trassiza» (deformació de la transcripció de l'hebreu per metàtesi. 1,8: Vulgata: «Mesraim» (transcripció de l'hebreu); hebreu: מִצִרַיִם (Misràyim) 'Egipte, els egipcis'; Egerton/ Colbert: «los egepcians / los egepsians». En 2,7, la traducció d'Egerton i Colbert «com peccà en

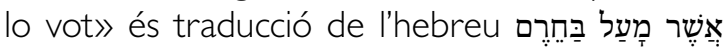
'que pecà/defraudà en el hérem / el que estava consagrat' i no de la Vulgata «et peccavit in furto anathematis». En 4,21, la traducció d'Egerton i Colbert «e los linatges/linages de Bet Abudabús, de la casa de Ber» és traducció corrompuda pels

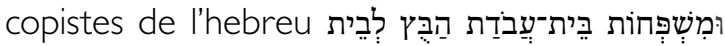

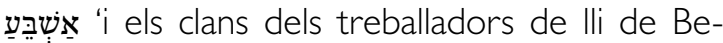
taixbea', en què els mots hebreus corresponents

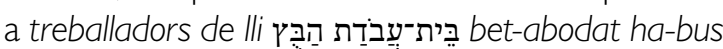
han estat presos com a nom propi i, per tant, transcrits en lloc de traduïts. Etc.

\section{Exemples de traduccions del Saltiri traduït de l'hebreu que segueixen l'original hebreu}

SI 2,2. Vulgata: «Astiterun reges terrae, et principes convenerun in unum adversus Dominum, et adversus christum ejus». Versió del saltiri: «Estigueren los reys de terra e prínceps s'avistaren ensemps sobre lo Senyor, sobre son untat». La preposició sobre s'explica perquè tradueix el mot hebreu: ‘v, que té tant el sentit de 'sobre' com de 'contra'.

SI 3,8. Vulgata: «Percussisti omnes adversantes mihi sine causa.» Versió del saltiri: «Firiràs a tots los meus enemichs en la galta.» Els mots la galta tradueixen literalment el mot hebreu: לֶ. 'galta'.

SI 8,6. Vulgata: «Minuisti eum paulo minus ab angelis.» Versió del saltiri: «E has-lo minvat poch de Déu.» La traducció catalana segueix el text he-

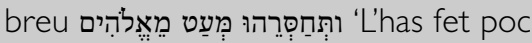
menys que un déu'. 
Aquestes parts traduïdes de l'hebreu ens fan veure que els manuscrits Egerton i Colbert han de tenir un arquetipus comú. Al nostre entendre, el més probable és que aquest arquetipus incorporés totes aquestes parts traduides de l'hebreu i que, posteriorment, un altre copista previ a Egerton (o el d'Egerton mateix) retornés a la traducció de la Vulgata els capítols de Josuè 18-24. Ens sembla menys probable que aquest arquetipus incorporés de la versió de l'hebreu només el text del Primer llibre dels Paralipòmens i que, després, un copista de la branca de Colbert o el mateix copista de Colbert hi incorporés el text de Josuè $18-24 .^{15}$

No és gaire versemblant que aquestes parts traduïdes de l'hebreu siguin obra d'un copista que, no estant satisfet de la versió feta a partir de la Vulgata que tenia a l'original que copiava, volgués fer-la de nou ell mateix a partir de l'hebreu. En canvi, sembla que era un procediment normal que alguns copistes disposessin de més d'un model i anessin triant les variants textuals que consideraven més idònies (Alturo 2003: 250). En el cas de la Bíblia del segle XIV, podem suposar que el copista es va trobar que el model traduït del llatí que copiava estava en mal estat, o bé no el satisfeia el seu contingut. I va optar per copiar determinats capítols o llibres d'un altre model, aquest traduït de l'hebreu.

Finalment, no és probable que existissin traduccions de l'hebreu de llibres molt secundaris dins del corpus dels llibres de la Bíblia hebrea, com són els Paralipòmens o Cròniques, si no és formant part d'un Antic Testament complet traduiit de l'hebreu —sí que podríem esperar traduccions d'altres llibres bíblics solts, com serien els Salms o bé el conjunt del Pentateuc. De fet, sabem que en

15. Sigui com sigui, tot això ens fa veure la impossibilitat de l'stemma proposat per Armand Puig a l'estudi introductori al volum 3 del CBCat (2004: apartat 3.1.2, XLV-XLVII), segons el qual Peiresc i Colbert tindrien un subarquetip comú, del qual no dependria Egerton. Les llacunes comunes a P i C $($ Lv 8,$33 ; 13,48)$ es poden explicar fàcilment perquè un copista de la branca d'Egerton les va omplir, o bé traduint directament de la Vulgata o copiant d'un altre manuscrit bíblic. En canvi, tal com vam explicar en la introducció al vol. 6 del CBCat (2011: 17-18) hi ha diversos errors comuns a $\mathrm{E}$ i $\mathrm{C}$ que també postulen un subarquetip comú. època medieval existien una o més versions completes de l'Antic Testament traduit de l'hebreu al català. ${ }^{16}$ Si la versió pròpia, traduïda de la Vulgata, del manuscrit Egerton en Ex 1,1-Lv 2,2 i Lv 18,2-27,34 fos feta «a cavall entre els segles XIV i XV», com proposa Armand Puig (CBCat, vol. 3: XXXIII), aquest Antic Testament traduit de l'hebreu s'hauria de datar com a molt tard a la segona meitat del segle XIV, tenint en compte que va ser incorporat per un subarquetipus comú als manuscrits Egerton i Colbert, i per tant anterior a la incorporació només en la branca d'Egerton de la seva traducció pròpia. De tota manera, Puig no justifica la seva datació.

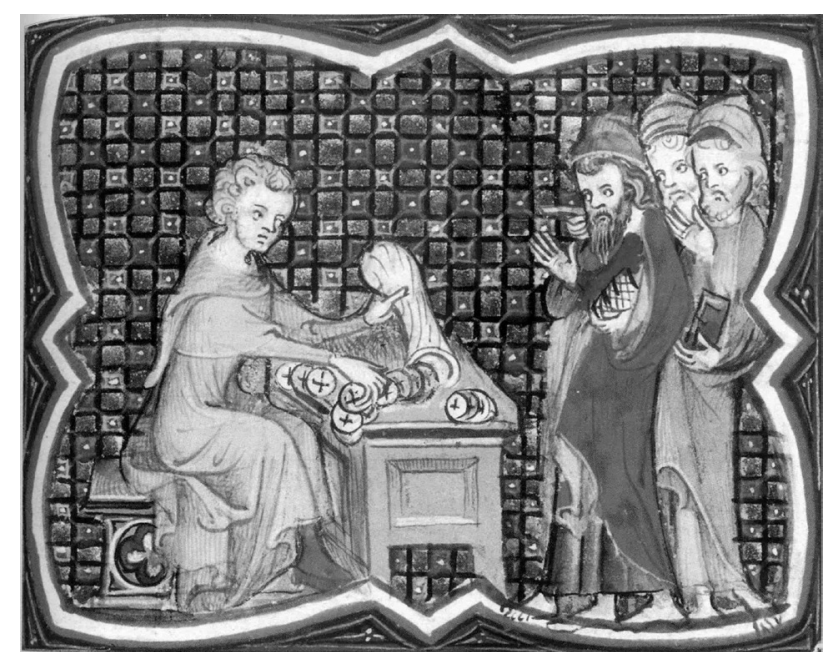

Recaptador d'impostos a la Biblia historiada de Guiart des Moulins (París, BNF).

Traduccions de l'hebreu com aquesta foren usades per conversos, i aquest és un dels motius que justificà la persecució de la Inquisició i la crema de bíblies, ja que se suposava que fomentaven l'heretgia judaïtzant. Ens sembla, però, que devien tenir l'origen en traduccions fetes per jueus per a l'ús de jueus amb poc coneixement de l'hebreu.

\section{Els quatre evangelis traduïts del català a l'hebreu}

7. Els evangelis van ser escrits en grec, o almenys es van conservar i es van difondre en grec - suposant que hi hagi hagut una primitiva versió de l'Evangeli de Mateu escrita en arameu, no s'ha conservat. No se'n coneix cap traducció dels primers

16. Vegeu Riera i Sans (2013: 44). 
segles a l'hebreu, i la primera traducció completa dels quatre evangelis a l'hebreu es troba en un manuscrit de la segona meitat del segle $X V$, escrit en lletra bizantina, que es troba actualment a la Biblioteca del Vaticà i que va ser compilat a Creta juntament amb dues obres més en hebreu. De data anterior només es coneix una versió a l'hebreu de l'Evangeli de Mateu, conservada en l'obra polèmica Even bohan («Pedra de toc») de Xem Tob ben Yishaq ibn Xaprut, de Tudela, escrita just abans dels avalots de l'estiu del 139|; la intenció era fer veure les contradiccions i defectes dels evangelis als seus correligionaris jueus per evitar que es convertissin al cristianisme. No sabem si Xem Tob va fer ell mateix aquesta traducció o si la va copiar d'algun altre manuscrit.

El manuscrit de la Vaticana amb els quatre evangelis és clarament una còpia de la traducció original, tot i que, lamentablement, no hi ha res en el manuscrit que ens permeti identificar ni el copista ni el traductor. I el que per a nosaltres és més sorprenent $\mathrm{i}$ interessant, és que aquesta traducció no està feta a partir de la Vulgata, ni de l'original grec, sinó del català. I és més, hem pogut identificar el text català en què es basa la traducció: és la Bíblia del segle XIV, en la versió conservada pel manuscrit Peiresc, la versió que estem publicant ara en diversos volums en el CBCat.

Umberto Cassuto, en el seu catàleg de manuscrits hebreus de la Biblioteca Vaticana (1956), va descriure el manuscrit i ja va apuntar que podia tractar-se d'una versió del català (144-45). L'any 1981 Maties Delcor, en un article publicat a l'Anuario de Filología, en va estudiar el capítol 10 de Mateu i va deduir que era traduït del català, però que el manuscrit havia estat corregit per un italià; també era de l'opinió que l'autor era un jueu convers i que la finalitat de la traducció era la conversió dels jueus. El nou catàleg de manuscrits hebreus de la Biblioteca Vaticana recull la informació del catàleg de Cassuto, hi afegeix que l'escriptura és bizantina semicursiva i que les marques d'aigua són iguals que les d'un manuscrit datat el 1479 (Richler 2008: 67). Delio Vania Proverbio, en la descripció del manuscrit publicada en un catàleg d'una exposició feta la Vaticà, explica que el còdex miscellani del qual forma part aquesta traducció procedeix de Creta, que havia format part de la biblioteca privada del bibliòfil jueu Elia Capsali (1482-1555) i remarca que es tracta d'un manuscrit de factura clarament jueva, i per aquest motiu no sembla que l'original del qual es va copiar la traducció hebrea dels evangelis pogués ser d'ús de cristians; per les diverses filigranes data el manuscrit de la segona meitat del segle $x v$ (Proverbio 2000).

Actualment tenim aquest manuscrit ja totalment transcrit per al CBCat, n'estem fent ara una traducció al català modern i l'estem anotant, i esperem que es pugui publicar aviat. Delcor, tot i haver-ne estudiat un sol capítol, anava força ben encaminat: la traducció original és clarament feta sobre un text català i va ser copiat per un escrivà de llengua italiana. Ara hi podem afegir que aquest text català és el mateix copiat en el manuscrit Peiresc de la Bíblia del segle XIV.

EL CATALÀ COM A LLENGUA ORIGINAL DE LA TRADUCCIÓ I LA ITALIANITZACIÓ DELS NOMS PROPIS INTRODUIIDA PELS COPISTES

7.1.1. Els noms propis, en general, apareixen clarament transcrits del català. Però de vegades, especialment en notes marginals o en els títols afegits pels copistes, apareixen italianitzats. Així, a la llista de Mateu 10,1-4, hi apareixen les formes següents per als noms dels apòstols: שימון Simon (que apareix dues vegades en la llista), פירי Pere, אנדריב Andreu, גיקמי Jacme (apareix dues vegades a la llista), זאבאדיב Zebedeu, זואיב Joan, טומאן Tomàs, קאנניב Cananeu, יודש Judes. En tres casos sembla que hi ha errors del copista: ברטומיב en Iloc de אבפיב Bartomeu ארטומיב en Iloc de אלפיב Alfeu, טאדיב Tadeu. Respecte a alguns dels noms anteriors (Andreu, Zebedeu, etc.), s'ha de tenir en compte que la terminació יביב (-yb) és la transcripció normal en hebreu del diftong del català medieval -eu. Alguns d'aquests noms podrien ser transcripció de noms escrits en altres llengües romàniques, especialment dialectes occitans, però com a conjunt només poden ser transcripcions del català.

Alguns d'aquests noms han estat corregits pel mateix copista del text al marge amb formes que pertanyen en general a dialectes italians medievals: פירי Pere $\rightarrow$ פירו Pere, אנדריב Andreu $\rightarrow$ 


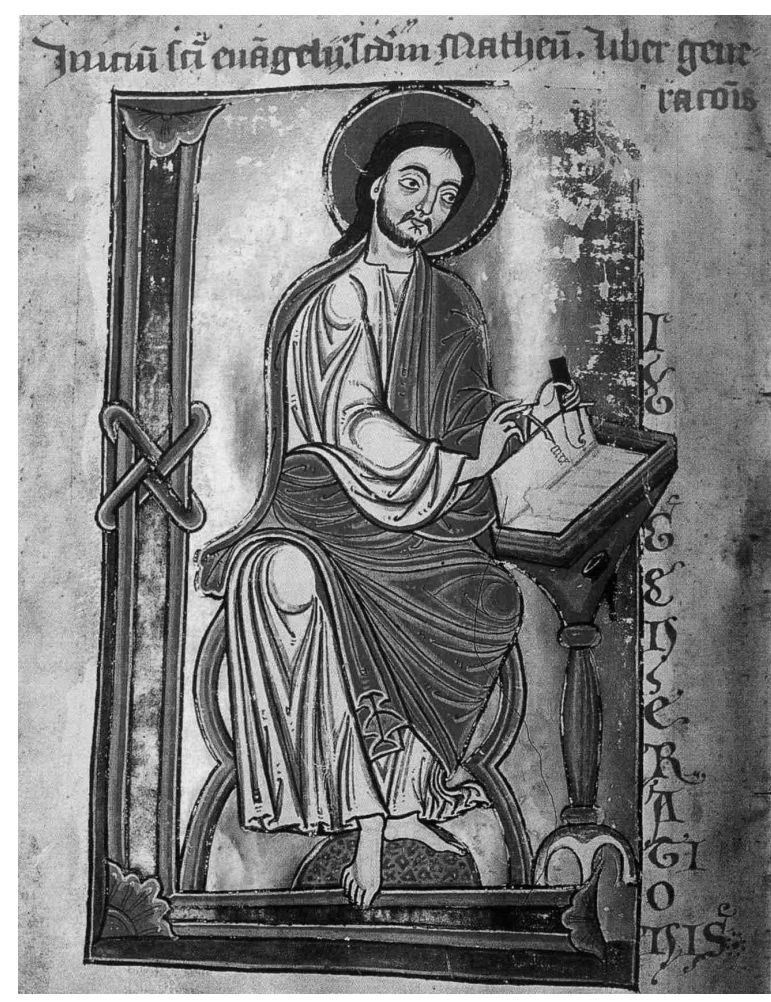

Sant Mateu escrivint l'evangeli (segle XII, Laon, Biblioteca municipal, ms. 550).

בורטולומיאו $\rightarrow$ Bartomeu ברטומי[ב] Bortolomeo, גיקמי Jacme $\rightarrow$ יקומו Jacomo.

En dos casos, la italianització dels noms ha estat feta en el text mateix: מטיאו Matteo (en lloc de מתיב O Mateu) i פיליפו Filippo (en Iloc de פליף o פיליף Felip). En tots dos casos aquests noms apareixen transcrits correctament del català en molts altres llocs dels evangelis. ${ }^{17}$

Finalment, en els títols del capítols, el nom de l'evangelista també ha estat italianitzat: מרקו Matteo. El mateix passa amb el nom מתיאו Marco en els títols de l'Evangeli de Marc (la transcripció catalana Marc hauria de ser מרק) i amb el nom לוקא Luca en els capítols de Lluc (la transcripció de Lluc hauria de ser ליוס). En canvi, és curiós que en els títols de Joan hi trobem

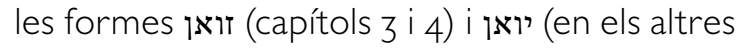
capítols) que no corresponen a la transcripció de la forma italiana Giovanni sinó de la forma catalana Joan.

17. ביתמ en Mt 9,9; Expl; Mc 3,18; Lc Prol,6; 6,15; ויטמ en Mc 2,14; ריליפ en Jn 1,44.45; 11,43.46; 12,22; 14,8; en Mc 3,18; Jn 6,5.7; 12,21.22; 14,9.
7.1.2. En alguns casos, el traductor no va saber com traduir una paraula catalana a l'hebreu i es va limitar a transcriure-la; algunes d'aquestes transcripcions tenen puntuació (és a dir, els punts i ratlletes que acompanyen les consonants hebrees per a indicar les vocals) per ajudar en la pronunciació d'aquestes paraules no hebrees.

L'exemple més clar, a causa de la seva freqüència en el text, és el verb català escandalitzar (Vulgata: scandalizare) i el substantiu escàndol (Vulgata: scandalum). A la Vulgata hi ha 32 occurrències d'aquestes paraules. Cinc vegades (Mt 16,23; Lc 17,1.2; In 6,62; 16,1) han estat traduïdes de diverses maneres, però en la majoria de casos el traductor s'ha limitat a transcriure les paraules catalanes en caràcters hebreus. Ho podem veure en el text de Mt 26,31-33 (diàleg entre Jesús i Pere just després de l'últim sopar, després que Jesús hagi anunciat als deixebles que el negaran) en la traducció hebrea comparada amb el text de la Vulgata:

$$
\begin{aligned}
& \text { כיכד אמר ישו לתלמידיו } \\
& \text { כולכם תהיו אישקנדליזאטש }
\end{aligned}
$$

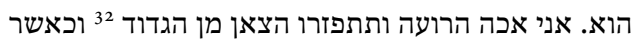

$$
\begin{aligned}
& \text { אהיה קם חי אהיה לפניכם בגליליאה: } \\
& \text { ואנה פירו פם ואירו ואמר אליו } \\
& \text { ואם כולם יהיו אישקנדליזאטש בעלור בעבורך אני לעולם לא אהיה } \\
& \text { אישקנדליזט }
\end{aligned}
$$

Els mots hebreus תהיו אישקנדליזאטש no són una traducció de l'expressió llatina scandalum patiemini 'sofrireu un escàndol' sinó que corresponen als mots catalans sereu escandalitzats: el verb sereu ha esta traduit i el participi escandalitzats ha estat transcrit. El mateix passa en el cas de יהיו אישקנדליזאטש (que correspon als mots catalans seran escandalitzats, cf. Vg. scandalizati fuerint) i אהיה אישקנדליזט (seré escandalitzat, cf. Vg. scandalizabor). 
Formes similars del verb català escandalitzar transcrites en lletres hebrees, de vegades amb petits errors de còpia, apareixen en vint llocs més. ${ }^{18}$

En Mateu 6,1, el traductor ha tingut dificultat per a traduir la paraula catalana ufana, en el sentit de 'ostentació': primer ha intentat traduir-la fent servir la paraula aramea אמבוה 'multitud' i immediatament després transcriu el mot original català ufana (precedit per l'expressió en vulgar):

השמרו לבלתי עשות אמבוה בלעז אופנא. ממעשיכם

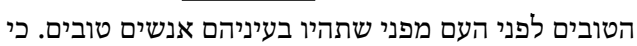
תאבדו גמול אביכם שבשמים מפני שתיות

Attendite ne justitiam vestram faciatis coram hominibus, ut videamini ab eis: alioquin mercedem non habebitis apud Patrem vestrum qui in caelis est.

Heus aquí alguns altres exemples de paraules catalanes transcrites al text hebreu: אונגילי, איונגלי evangeli (Mt Prol,4.7.11); איונגלישטש evangelistes (Mt Prol,17); ויבריש > ויבדיש vibres 'escurçons' (Mt 3,7);

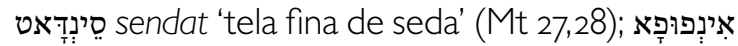
en (la) popa (Mc 4,37).

D'acord amb el que hem dit dels títols dels capítols, la paraula corresponent a capítol que apareix en aquests títols sempre és transcrita de l'italià: קפיטולו capitolo.

7.1.3. Altres detalls del text hebreu mostren que no ha estat traduit del text llatí de la Vulgata i reflecteixen, sovint amb precisió, les diferents característiques de l'original català.

Les formes passives de la Vulgata corresponen, en la traducció hebrea, a formes perifràstiques que reflecteixen les formes passives perifràstiques d'una llengua romànica. Ho podem veure en tres exemples presos de l'inici de l'Evangeli de Joan (entre parèntesis indiquem les formes sintètiques hebrees que hauríem d'esperar si la traducció hagués estat feta a partir del llatí, vegeu el quadre 3).

Les consonants oclusives finals $-b,-d i$-g dels noms propis, de vegades es transcriuen fent ser-

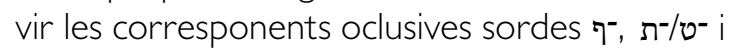
$\mathrm{P}^{-}$, d'acord amb la pronunciació més usual en

18. Mt $5,29.30 ; 11,6 ; 13,41.57 ; 15,12 ; 18,6.7^{\times 3} .8 .9 ;$ Mc 6,3; 9,41.42.44.46; 14,27.29; Lc 7,23. català d'aquestes consonants (excepte davant de consonant sonora, vegeu el quadre 4).

Algunes traduccions errònies s'expliquen fàcilment quan sabem que el text original és el català. Entre els moltíssims exemples que podríem esmentar, n'escollim tres presos dels primers capítols de Mateu.

(a) En Mt 4,23, la Vulgata diu: «Et circuibat Jesus totam Galilaeam, docens in synagogis eorum, et praedicans Evangelium regni», és a dir: 'I Jesús recorria tota Galilea, ensenyant en Ilurs sinagogues i predicant l'evangeli del regne'. Però la traישואש משיח היה מחפש כל ארץ ducció hebrea diu '.... גלילאה 'Jesucrist cercava tot el país de Galilea...', cosa que no expressa el sentit correcte del text neotestamentari. El traductor ha traduït barroerament el verb del català antic cercava, que tenia el sentit que té aquest verb en català modern, sinònim de buscar, però que també tenia el sentit de 'recórrer', que és el que correspon aquí.

(b) En Mt 6,10, la traducció hebrea dolenta (Que) vingui al teu regne!' en Iloc de ויבא מלכותך '(Que) vingui el teu regne!' es pot explicar perquè en català oriental en el segle XV les vocals a i e en síllaba àtona ja es pronunciaven en totes les posicions com a vocal neutra [ə] i sovint es confonien en els manuscrits. El manuscrit català probablement tenia Que vingui al teu Regne (al és, de fet, el que té el manuscrit Peiresc, del qual tractem en el pròxim apartat) en lloc de Que vingui el teu Regne.

ומי מכם יכול : En Mt 6,27, el text hebreu diu I qui de vosaltres pot afegir una mesura a la vida del seu cos?', la qual cosa no té gaire sentit. La Vulgata diu: 'Quis autem vestrum cogitans potest adjicere ad staturam suam cubitum unum'. El manuscrit Peiresc de la Bíblia del segle XIV ha traduit correctament staturam per mida, però en algun manuscrit la lletra $m$ va ser llegida com a $u$, i el resultat va ser uida, és a dir, regularitzant la grafia, vida, la paraula que va ser traduïda en hebreu per [0] חיים.

Curiosament, almenys en un cas (Mt 11,22) una coordinació de dos noms propis apareix transcrita, incloent-hi la conjunció i les dues preposicions, del català a l'hebreu en lloc de ser traduïda: vegeu el quadre 5). 


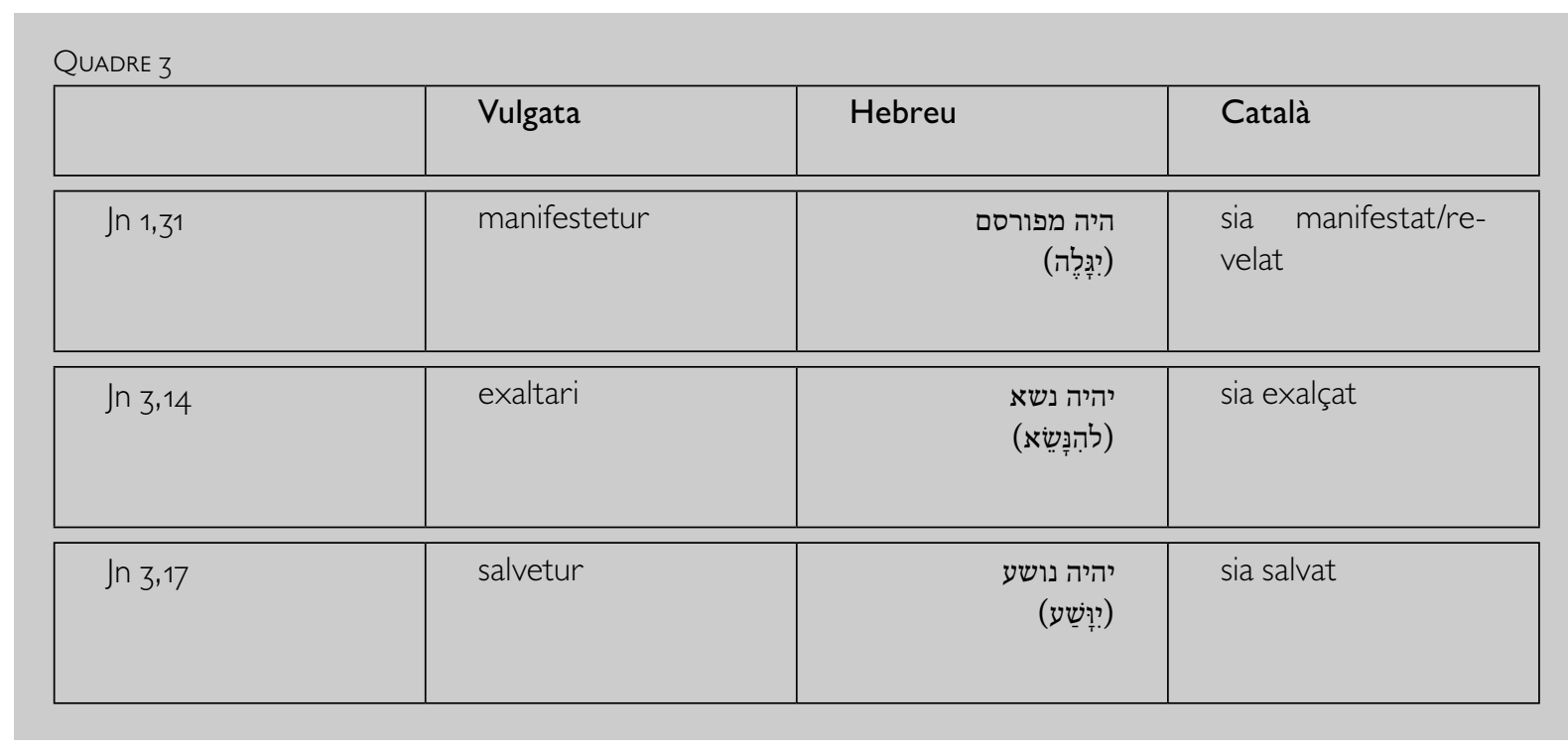

QUADRE 4

\begin{tabular}{|l|l|l|l|}
\hline & $\begin{array}{l}\text { Vulgata sixtocle- } \\
\text { mentina }\end{array}$ & Hebreu & \\
\hline Mt 1,4 & Aminadab & אמינדף & $-b \rightarrow \eta^{-}(-p)$ \\
\hline Mt 1,14 & Eliud & $-d \rightarrow 0^{-/ ת^{-}(-t)}$ \\
\hline Lc 3,35 & Sarug & $-g \rightarrow \nabla^{-}(-c)$ \\
\hline
\end{tabular}

\section{LA BíBLIA DEL SEGLE XIV COM A ORIGINAL DE LA TRADUCCIÓ}

7.2. Entre les diverses versions bíbliques catalanes conservades, disposem de tres manuscrits complets dels evangelis:

1. Els Evangelis del Palau o Còdex del Palau, que data de la primera meitat del segle $X V^{19}$

2. El manuscrit Marmoutier, de mitjan segle XIV, que conté tot el Nou Testament. ${ }^{20}$

3. El manuscrit Peiresc, que conté tota la Bíblia i va ser copiat aproximadament entre 1460 i $1470 .{ }^{21}$

Els manuscrits Peiresc i Marmoutier pertanyen a la Bíblia del segle XIV, esmentada més amunt (§ 4). El text contingut en Peiresc va ser copiat diverses vegades entre la data de la traducció (primera meitat del segle XIV) i la data del manuscrit (1460-70), i entre els manuscrits

19. Sant Cugat del Vallès, Arxiu Nacional de Catalunya, Ms. ANC1-960-T-1038 [fons Requesens-Palau]. 20.París, Bibliothèque Nationale de France, ms. esp. 486. 21. París, Bibliothèque Nationale de France, ms. esp. 2, 3 i 4.
Peiresc i Marmoutier hi ha abundants i considerables diferències textuals.

La comparació de la traducció a l'hebreu dels evangelis i el text d'aquests tres manuscrits mostra que la traducció que recull el manuscrit Peiresc constitueix l'original de la versió hebrea. Tot i això, la traducció hebrea sovint s'aparta de Peiresc, perquè devia ser feta d'un manuscrit més antic que Peiresc i que contenia múltiples variants respecte d'aquest manuscrit.

La dependència del manuscrit Peiresc es manifesta en primer lloc en els pròlegs. A l'edat mitjana els evangelis s'acostumaven a copiar amb pròlegs llatins medievals de diversos orígens, alguns procedents de sant Jeroni. Els pròlegs dels evangelis en hebreu, basats en part en la introducció de sant Jeroni al seu comentari sobre Mateu, coincideixen del tot amb els de Peiresc, tret que hi falta el de l'Evangeli de Joan. I tenint en compte la varietat de pròlegs que hi havia, això ja és un bon indici de depèndència de l'hebreu respecte a la versió de la Bíblia del 


QUADRE 5
\begin{tabular}{|l|l|l|}
\hline Vulgata & Hebreu & Català \\
\hline Tyro et Sidoni & & de Tir e [0 bé: i] de Sidon \\
\hline
\end{tabular}

\section{QUADRE 6}

\begin{tabular}{|c|c|c|}
\hline Vulgata i trad. literal & Hebreu i trad. literal & Peiresc \\
\hline $\begin{array}{l}\text { Videns autem turbas, miser- } \\
\text { tus est eis: quia erant vexati, } \\
\text { et jacentes sicut oves non } \\
\text { habentes pastorem. Tunc } \\
\text { dicit discipulis suis }\end{array}$ & 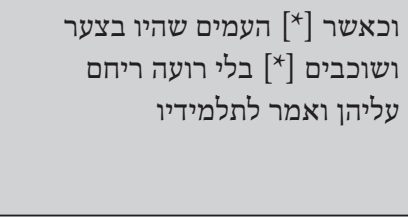 & $\begin{array}{l}\text { E quant [*] les gens qui éran } \\
\text { traballades e éran [*] sens } \\
\text { pastor, hach piatat d'ells, e } \\
\text { dix alls dexebles }\end{array}$ \\
\hline $\begin{array}{l}\text { 'I veient les multituds, en } \\
\text { va tenir compassió: perquè } \\
\text { estaven malmenades i jeien } \\
\text { com ovelles que no tenen } \\
\text { pastor. Llavors va dir als seus } \\
\text { deixebles' }\end{array}$ & $\begin{array}{l}\text { 'I quan [*] les gents que esta- } \\
\text { ven afligides i jeien [*] sense } \\
\text { pastor, se'n va compadir i va } \\
\text { dir als seus deixebles' }\end{array}$ & \\
\hline
\end{tabular}

\section{QUADRE 7}

\begin{tabular}{|c|c|c|}
\hline Vulgata i trad. literal & Hebreu i trad. literal & Peiresc \\
\hline $\begin{array}{l}\text { Et exuentes eum clamydem } \\
\text { coccineam circumdederunt } \\
\text { ei. }\end{array}$ & 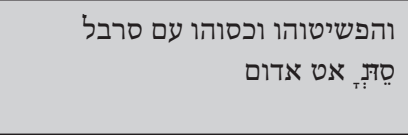 & $\begin{array}{l}\text { E daspulàran-lo, e abrigà- } \\
\text { ran-lo da un mantell de san- } \\
\text { dat vermell. }\end{array}$ \\
\hline $\begin{array}{l}\text { 'I despullant-lo, el van cobrir } \\
\text { amb un mantell escarlata.' }\end{array}$ & $\begin{array}{l}\text { 'I el van despullar i el van co- } \\
\text { brir amb un mantell de sen- } \\
\text { dat vermell.'. }\end{array}$ & \\
\hline
\end{tabular}

\section{QUADRE 8}

\begin{tabular}{|c|c|c|}
\hline Vulgata i trad. literal & Hebreu i trad. literal & Peiresc \\
\hline $\begin{array}{l}\text { Non in solo pane vivit homo, } \\
\text { sed in omni verbo, quod } \\
\text { procedit de ore Dei. }\end{array}$ & מחדם אינינו חי על הלחם לבדו אבל & $\begin{array}{l}\text { Hom no viu tan solament de } \\
\text { pa, mes de la gràcia de Déu. }\end{array}$ \\
\hline $\begin{array}{l}\text { 'No sols de pa viu l'home, } \\
\text { sinó de tota paraula que } \\
\text { procedeix de la boca de } \\
\text { Déu.' }\end{array}$ & $\begin{array}{l}\text { 'L'home no viu de solament } \\
\text { de pa, sinó de la gràcia de } \\
\text { DÉu [literalment: del Nom].' }\end{array}$ & \\
\hline
\end{tabular}

\section{QUADRE 9}

\begin{tabular}{|l|l|l|}
\hline Vulgata i trad. literal & Hebreu i trad. literal & Peiresc \\
\hline $\begin{array}{l}\text { Tu autem, cum jejunas, unge } \\
\text { caput tuum, et faciem tuam } \\
\text { lava. }\end{array}$ & $\begin{array}{l}\text { Mas com tu dejunes, pantina } \\
\text { ton cap e lava ta cara. }\end{array}$ \\
\hline $\begin{array}{l}\text { 'Però tu, quan dejunes, un- } \\
\text { geix el teu cap i renta la teva } \\
\text { cara.' }\end{array}$ & $\begin{array}{l}\text { 'Però tu, quan dejunis, pen- } \\
\text { tina el teu cap i renta la teva } \\
\text { cara.' }\end{array}$ & \\
\hline
\end{tabular}


segle XIV recollida per Peiresc. Però encara hi ha indicis més clars i concloents. Mentre que en e pròleg llatí, Mateu és qualificat de levita, tant en la versió hebrea com en Peiresc això es diu de Marc. En el pròleg llatí, Joan escriu per defensar el cristianisme enfront dels heretges, mentre que en la versió hebrea i en Peiresc això es diu de Mateu. La tradició que Marc va amputar-se un dels dits per no ser apte per a treballar al temple com a sacerdot es troba en la versió hebrea i en Peiresc, però no en el text llatí; etc. ${ }^{22}$

Pel que fa al text dels evangelis en ell mateix, una comparació atenta del text hebreu amb el text del manuscrit Peiresc i amb la Vulgata mostra clarament que la traducció hebrea va ser feta a partir d'un mauscrit que contenia la mateixa traducció que es va copiar, amb molts errors, variants i llacunes, en el manuscrit Peiresc. En veurem alguns exemples presos de l'Evangeli de Mateu.

Algunes omissions que trobem en el text hebreu també es troben en Peiresc. En alguns casos això és especialment notable perquè l'omissió fa que el text sigui gramaticalment incorrecte, com passa en la primera de les dues omissions de $\mathrm{Mt}$ 9,36-37. Observeu, a més, que la traducció hebrea segueix l'ordre de les paraules de Peiresc (vegeu el quadre 6).

Els afegitons respecte al text de la Vulgata que trobem en la traducció hebrea, normalment també es troben en el manuscrit Peiresc. La presència en el text de Mt 27,28 de la paraula catalana sendat, a què ens hem referit més amunt $(\S$ 7.1.2) és una d'aquestes — en aquest cas petitaaddició (també es pot considerar com a formant part d'una traducció parafràstica del mot llatí coccineam) (vegeu el quadre 7).

En alguns casos, la traducció difereix considerablement del text de la Vulgata i coincideix amb Peiresc, com en la segona part de Mt 4,4: (vegeu el quadre 8).

La diferència només afecta un verb en Mt 6,17 (el text hebreu i Peiresc coincideixen en formes que signifiquen 'pentinar', enfront de la Vulgata, que té unge 'ungeix') (vegeu el quadre 9).

22. Sobre els pròlegs, vegeu amb més detall Hames (2012: 290-93).
En alguns casos, la diferència respecte a la Vulgata prové d'un error de copista en un manuscrit de la Bíblia del segle XIV. És el que passa, per exemple, en Mt 8,12, on la paraula dens (mala grafia per dents; vegeu dues paraules abans en Peiresc tramolamens en lloc de tremolaments) va ser llegida i copiada per un escrivà com a deus, forma del català antic corresponent a la moderna Déu (vegeu el quadre 10):

De vegades la diferència entre la traducció hebrea i la Vulgata es deu al fet que el traductor hebreu ha entès malament el text català de la Bíblia del segle XIV. És el cas de Mt 10,17, on el substantiu parlament, que tenia el significat d"assemblea' dins el seu context, ha estat entès erròniament pel traductor com a 'discursos, paraules' (significat que el mot té certament en altres contextos (vegeu el quadre 11):

En diversos llocs, la versió hebrea fa possible la correcció d'errors del manuscrit Peiresc, un manuscrit molt defectuós com ja hem fet notar. L'exemple següent és de Mt 6,22 (vegeu el quadre 12).

La paraula del final del verset 22 del manuscrit Peiresc no fa sentit i no correspon a l'adjectu llatí lucidum 'lluminós, clar, resplendent'. En els manuscrits medievals catalans les lletres $r$ i t sovint són molt similars i es confonen, i el grup $\mathrm{cl}$ - fàcilment es pot confondre amb la lletra $d$-. És molt probable, doncs, que l'original de la Bíblia del segle XIV tingués clar en lloc de dat, i aquesta correcció s'hauria d'introduir al text del manuscrit Peiresc.

\section{L'AUTOR DE LA TRADUCCIÓ}

7.3. Al principi d'aquest capítol 7 hem vist que, mentre Delcor opinava que aquesta traducció havia estat feta per un jueu convers per a ús de cristians i amb finalitats de proselitisme, Proverbio creu que és obra de jueus. El nivell de coneixement de l'hebreu que suposa aquesta traducció fa molt difícil pensar que pogués ser obra d'un erudit d'origen cristià que hagués après l'hebreu. Però d'altra banda, hi apareixen alguns elements que sobten si se suposa un autor amb bons coneixements de la llengua hebrea. N'esmentarem dos. En primer lloc, les citacions de l'Antic Testament que contenen els evangelis no estan preses del text hebreu de l'Antic Testament — com cal- 


QuADRE 10
\begin{tabular}{|l|l|l|}
\hline Vulgata i trad. literal & Hebreu i trad. literal & Peiresc \\
\hline $\begin{array}{l}\text { Ibi erit fletus et stridor den- } \\
\text { tium. }\end{array}$ & \multicolumn{1}{|c|}{$\begin{array}{l}\text { Aquí serà plor e tramola- } \\
\text { mens de dents. }\end{array}$} \\
\hline $\begin{array}{l}\text { 'Allà hi haurà el plor i el crui- } \\
\text { xit de dents.' }\end{array}$ & $\begin{array}{l}\text { 'I allí hi haurà plor i tremolor } \\
\text { de Déu.' }\end{array}$ & \\
\hline
\end{tabular}

\section{QUADRE 11}

\begin{tabular}{|l|c|l|}
\hline Vulgata i trad. literal & Hebreu i trad. literal & Peiresc \\
\hline $\begin{array}{l}\text { Tradent enim vos in conciliis, } \\
\text { et in synagogis suis flagella- } \\
\text { bunt vos. }\end{array}$ & $\begin{array}{l}\text { car ells vos amenaran en lurs } \\
\text { perllaments, e abatran-vos } \\
\text { en lurs sinagogas, }\end{array}$ \\
\hline $\begin{array}{l}\text { 'Perquè us lliuraran a les as- } \\
\text { semblees, i us assotaran en }\end{array}$ & $\begin{array}{l}\text { 'Perquè us conduiran amb } \\
\text { semars paraules i us pegaran en } \\
\text { Ilurs sinagogues.' }\end{array}$ & \\
\hline
\end{tabular}

\section{QUADRE 12}

\begin{tabular}{|c|c|c|}
\hline Vulgata i trad. literal & Hebreu i trad. literal & Peiresc \\
\hline $\begin{array}{l}\text { Si oculus tuus fuerit simplex, } \\
\text { totum corpus tuum lucidum } \\
\text { erit. }\end{array}$ & אם עינך תמימה כל הגוף יהיה בהיר & $\begin{array}{l}\text { Si lo teu vull és simpla, tot lo } \\
\text { teu cors serà dat. }\end{array}$ \\
\hline $\begin{array}{l}\text { 'Si el teu ull és simple, tot el } \\
\text { teu cos serà lluminós.' }\end{array}$ & $\begin{array}{l}\text { 'Si el teu ull és simple, tot el } \\
\text { teu cos serà brillant/clar.' }\end{array}$ & \\
\hline
\end{tabular}

dria esperar de qualsevol traductor familiaritzat amb la llengua i la cultura hebrees-, sinó que estan retraduïdes a l'hebreu des del text català de la Bíblia del segle XIV. En segon Iloc, hi apareixen algunes construccions impròpies de la llengua hebrea, la principal de les quals és potser la manera com es tradueix sovint Esperit Sant: הקודש רוח (ha-Qódeix Rúah), que és un calc, totalment agramatical en hebreu, de la forma més corrent en Peiresc Sant Esperit, enfront de la forma correcta רוח הקודש (Rúah ha-Qódeix), una expressió ben corrent en hebreu (i que es troba al mateix text bíblic: Is 63,10.11; SI 51,13). Pinhas Lapide en concloïa que es tracta d'una traducció imposada a un jueu que l'havia boicotejat introduint-hi aquests elements que l'estrafan (Lapide 1976: 64).

Probablement cal pensar que és una traducció feta per jueus per a ús de jueus (per combatre les conversions massives de jueus al cristianisme) i que la retraducció de les citacions de l'Antic Testament o la introducció d'algunes construcci- ons hebrees estranyes poden haver estat fetes intencionadament per allunyar els evangelis cristians de l'Antic Testament hebreu. Un detall de la traducció ens confirmaria que és així, si no ha estat afegit per un copista jueu. Es tracta de l'afegit que trobem en Lc 9,43 (vegeu el quadre 13).

Sobre aquesta qüestió de l'autoria, es pot consultar amb profit l'opinió matisada de Harvey Hames, que aporta algun detall més a favor de l'autoria jueva (2012: 295-300).

\section{Conclusions}

1. Jueus i jueus conversos tenien en territori català la llengua catalana com a llengua pròpia i un bon coneixement de l'hebreu com a llengua d'estudi i de pregària, la qual cosa els feia ben aptes per a la tasca de la traducció bíblica de l'hebreu al català o del català a l'hebreu. A més, molts contemporanis seus van excellir com a traductors, principalment de l'àrab, el llatí o el català a l'hebreu o al català. 


\begin{tabular}{|c|c|c|}
\hline \multicolumn{3}{|l|}{ QUADRE 13} \\
\hline Vulgata i trad. literal & Hebreu i trad. literal & Peiresc \\
\hline $\begin{array}{l}\text { Et increpavit Jesus spiritum } \\
\text { immundum, et sanavit pue- } \\
\text { rum, et reddidit illum patri } \\
\text { ejus. }\end{array}$ & 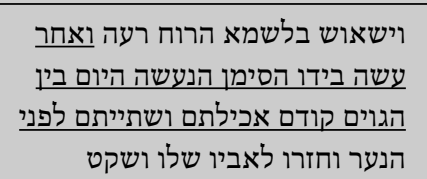 & $\begin{array}{l}\text { E Jesús blasmà l'asparit leig, e } \\
\text { sanà l'infant, e raté-lo a son } \\
\text { para. }\end{array}$ \\
\hline $\begin{array}{l}\text { 'I Jesús va increpar l'esperit } \\
\text { immund, i va sanar el noi, i el } \\
\text { va tornar al seu pare.' }\end{array}$ & $\begin{array}{l}\text { 'I Jesús blasmà l'esperit do- } \\
\text { lent i després va fer amb la } \\
\text { seva mà el signe que es fa } \\
\text { avui entre els cristians abans } \\
\text { de menjar i de beure davant } \\
\text { el noi i el va tornar al seu } \\
\text { pare, i estigué tranquil.' }\end{array}$ & \\
\hline
\end{tabular}

2. Tenim documentada la intervenció de dos jueus conversos com a promotors de la impressió, i d'un d'ells com a revisor, en la preparació per a la impremta de la Bíblia del segle Xv o Bíblia Valenciana.

3. Les influències hebraiques, bíbliques i fins i tot rabíniques que trobem en parts de la Bíblia del segle XIV s'expliquen fàcilment si la traducció va ser obra de jueus conversos que, tot i que traduïen per encàrrec de cristians, introduïen elements hebraics bíblics, i fins i tot alguns de la tradició rabínica, a les seves traduccions.

4. Hi va haver també algunes traduccions bíbliques, concretament de conjunts de salms, fetes o reelaborades per conversos jueus i destinades a l'ús dels conversos, incloses en manuals i llibres de pregàries per a ús de conversos.

5. No sols hi ha referències documentals a traduccions catalanes directes de l'Antic Testament hebreu al català, sinó que es poden identificar parts d'una d'aquestes traduccions en alguns dels manuscrits que contenen la Bíblia del segle XIV; aquestes parts no s'expliquen sense formar part d'un Antic Testament sencer. A més, conservem també un saltiri traduitt de l'hebreu.

6. Els quatre evangelis en hebreu, conservats en un manuscrit de la segona meitat del segle $\times v i$ que van ser traduïts de la Bíblia del segle XIV, molt probablement van ser traduïts per jueus o per jueus conversos. És plausible que fossin traduïts per jueus per a ús de jueus en el seu intent d'evitar les conversions al cristianisme. 


\section{Bibliografia citada}

Alturo I Perucho, Jesús, 2003: Història del llibre manuscrit a Catalunya, Barcelona: Generalitat de Catalunya, Entitat Autònoma del Diari Oficial i de Publicacions.

BERGER, Samuel, 1889-99: La Bible romane au Moyen Âge : Bibles provençales, vaudoises, catalanes, italiennes, castillanes et portugaises (Ginebra: Slatkine, 1977).

BOHIGAS, Pere, 1985: Sobre manuscrits i biblioteques, Barcelona: Curial Publicacions de l'Abadia de Montserrat.

Casanellas I Bassols, Pere, 2005: «El Corpus Biblicum Catalanicum: Un antic tresor que finalment comença a ser explotat», Llengua \& Literatura, 16, 517-30.

CASANellas I BAssols, Pere, 2006: «La influència hebraica en la Bíblia del segle XIV》, Revista Catalana de Teologia, 31, 347-58.

CAssuto, Umberto, 1956: Codices Vaticani hebraici: Codices 1-115, Ciutat del Vaticà.

CBCat, vol. 3: Bíblia del segle XIv: Èxode. Levític. Transcripció Jaume Riera i Sans; aparats crítics, notes i glossari Pere Casanellas i Bassols; estudi introductori Armand Puig i Tàrrech, Barcelona: Associació Bíblica de Catalunya - Publicacions de l'Abadia de Montserrat, 2004.

CBCat, vol. 6: Bíblia del segle XIv: Primer i segon llibre dels Reis. Transcripció i glossari Jordi Bruguera i Talleda; notes i introducció Pere Casanellas i Jordi Bruguera i Talleda; collació de vulgates catalanollenguadocianes Núria Calafell i Sala, Barcelona: Associació Bíblica de Catalunya - Publicacions de l'Abadia de Montserrat, 2011

Delcor, Maties, 1981: «Un manuscrit hébraïque inédit des quatre évangiles conservé a la Bibliothèque Vaticane (Hebr.100)», Anuario de Filología, 7, 201-19.
FelIU, Eduard, 2006-07: «Les traduccions hebrees del Regiment de sanitat d'Arnau de Vilanova», Tamid, 6, 45-141.

Feliu, Eduard \& Jon Arrizabalaga, 2000-01: «El pròleg de Semtov ben Issac, el Tortosí, a la seva traducció hebrea del Tașrîf d'Abu-l-Qāsim al-Zahrawì̀, Tamid, 3, 65-95.

GUTWIRTH, E., 1988: «Religión, historia y las biblias romanceadas», Revisto Catalana de Teologia, 13, 115-33.

HAMES, Harvey, 2012: «Translated from Catalan: Looking at a fifteenthcentury Hebrew version of the Gospels», El saber i les llengües vernacles a l'època de Llull i Eiximenis: Estudis ICREA sobre vernacularització $=$ Knowledge and vernacular languages in the age of Llull and Eiximenis: ICREA studies on vernacularization, eds. Anna Albern \& al., Barcelona: Publicacions de l'Abadia de Montserrat, 285-302.

LAPIDE, Pinchas E., 1976: Hebräisch in den Kirchen, Neukirchen-Vluyn: Neukirchener.

Muntané i Santiveri, Josep Xavier (ed.) 2010: Moixé Natán, Qüestions de vida, Barcelona: PPU.

Planas, Silvia \& Manuel Forcano, 2009: Història de la Catalunya jueva: Vida i mort de les comunitats jueves de la Catalunya medieval. Fotografies de Josep M. Oliveras. Girona: Ajuntament de Girona; Barcelona: Àmbit Serveis Editorials.

Proverbio, Delio Vania, 200o: «Vangeli. Ebraico», I Vangeli dei Popoli: La Parola e l'immagine del Cristo nelle culture e nella storia, eds. Francesco D'Aiuto, Giovanni Morello, Ambrogio M. Piazzoni, Ciutat del Vaticà: Biblioteca Apostolica Vaticana - Edizioni Rinnovamento nello Spirito Santo, $372-74$.
PUIG I TÀrReCH, Armand, 2001: «Les traduccions catalanes medievals de la Bíblia», en El text: lectures i història (Scripta Biblica 3), Barcelona: Publicacions de l'Abadia de Montserrat, 107-231.

Richler, Benjamin (ed.), 2008: Hebrew Manuscripts in the Vatican Library. Catalogue, comp. Institute of Microfilmed Hebrew Manuscripts in the Jewish National and University Library, Jerusalem; descripció paleogràfica i codicològica Malachi Beit-Arié i Nurit Pasternak, Ciutat del Vaticà: Biblioteca Apostolica Vaticana.

Riera I SANS, Jaume, 1971-75: «Un recull d'oracions en català dels conversos jueus (segle Xv)», Estudis Romànics, 16, 49-97.

Riera I Sans, Jaume, 1993: El siddur en català dels conversos jueus (segle Xv), Barcelona: Reial Acadèmia Catalana de Belles Arts de Sant Jordi.

RIERA I SANS, Jaume, 2011-12: «Els jueus dins el context català dels segles XIV i XV»), Lambard. Estudis d'art medieval, 23, 9-41.

RierA I SANS, Jaume, 2013: «Bíblies en català no cremades per la Inquisició espanyola»», Butlletí de l'Associació Bíblica de Catalunya, 115, 41-70.

VentURA, Jordi, 1993: La Bíblia valenciana. Recuperació de la història d'un incunable en català, Barcelona: Curial. 